\title{
Prevalence and Distribution of Root Caries in Chronic Liver Diseased Saudi Patients
}

\author{
Hana M. Jamjoom*, BDSc. MSc. \\ Department of Conservative Dental Sciences, \\ Faculty of Dentistry \\ King Abdulaziz University, Jeddah, Saudi Arabia \\ hjamjoom@hotmail.com
}

\begin{abstract}
Although root caries is found among patients of all ages, it demonstrates an increase in incidence with advancing age. Patients with liver diseases suffer from altered immunity and several disorders that may result in hyposalivation leading to dental caries. Patients with diagnosed viral and non-viral hepatitis were clinically examined for presence of root caries or filled root lesions and Root Caries Index was calculated for each patient. Demographic data and whole unstimulated saliva collected over a recorded time at mid-morning were obtained and salivary flow rate for each patient was calculated. For 114 chronic liver diseased patients and 50 controls, the mean values of Root Caries Index were 2.50 and 0.34 ; whereas, the saliva flow rate values were 0.34 and 0.48 , respectively. Root Caries Index increased with age, being higher among males than females $2.9,2.3$, respectively. The percentage of missing teeth was $45 \%$ and decayed teeth were $43 \%$. In conclusion, root caries index was significantly correlated to age and gender with higher incidence among male patients, and in the buccal surface of posterior teeth.
\end{abstract}

Keywords: Root caries, Liver disease, Salivary flow, Hepatitis, Pattern, Distribution.

\footnotetext{
${ }^{*}$ Correspondence \& reprint requests to: Dr. Hana M. Jamjoom

P.O. Box 51871, Jeddah, 21553 Saudi Arabia
}

Accepted for publication: 01 October 2006. Received: 04 June 2006 


\section{Introduction}

Root caries has become a significant oral health problem for older adults, this is due in part to the increase in the number of elderly surviving to an advance age with partially or fully dentate mouth. Longer retention of teeth will naturally result in an increased prevalence of dental caries and development of periodontal disease as loss of periodontal attachment and subsequently root exposure in the large proportion of surviving root surface ${ }^{[1-4]}$. This contributes to caries or other oral problems for older dentate patients ${ }^{[5]}$. It was reported that $98.9 \%$ of patients aged above 35-years have root surface with gingival recession, and $78.1 \%$ had at least one carious lesion ${ }^{[6]}$.

Elderly people commonly suffer from one or more chronic medical conditions that result in decreased salivary quantity and altered salivary character owing to disease or medication use ${ }^{[7,8]}$, the frequency of prescribed medication is reported to increase with age advancement ${ }^{[7]}$. Chronic disease can be a contributor to diminished oral hygiene efficacy because of impairments in functions such as vision or manual dexterity ${ }^{[5]}$.

It was previously reported that patients with chronic liver diseases (CLD) are more susceptible to bacterial infections that may lead to serious complications ${ }^{[9]}$. Increase of the incidence of oral bacterial infections such as: periodontal diseases, dental caries and sialadenitis has encouraged many investigators to evaluate dental findings in patients with liver diseases ${ }^{[10-13]}$. However, most of the studies have focused on oral mucosal lesions and periodontal disease; studies that examine dental root caries in hepatitis are rare. This is even true in Saudi Arabia and the neighboring Gulf States that are considered of moderate endemic for hepatitis B virus ${ }^{[14]}$.

The prevalence of root caries in the United States increases with age (18-75+) from $7 \%$ to $56 \%{ }^{[15]}$. Epidemiological data collection in northeast Germany reported increase in the percentage of root caries index (RCI) with age from $4.6 \%$ to $10.6 \%$ with a higher percentage of buccal-filled root surface ${ }^{[16]}$. Prevalence of root caries in Scandinavian countries, where cultural and nutritional habits are similar, varies from $30 \%$ in Finland ${ }^{[17]}$ to $80 \%$ in Sweden ${ }^{[18]}$ no risk factors were identified. Generally, risk factors of root caries are difficult to compare because of the variability in defining lesions and the challenge of diagnosing root caries.

In Saudi Arabia, data on the prevalence of root caries is scarce; the aim in this study was to assess the prevalence, pattern and distribution of root caries in chronic liver diseased patients and the relevence of age and gender on root caries among this group of patients. 


\section{Materials and Methods}

Participants were informed of the nature and the purposes of the study. Only those who gave their consent were included. Complete medical histories, demographic data, and age were collected during the dental examinations - only patients above 18-years of age were included. Patients were classified into:

A. Chronic Liver Disease (CLD) patients included patients attending King Abdulaziz University Hospital (KAUH) - Endoscope Unit. For each participant in the study, the diagnosis of chronic liver disease was based on laboratory blood investigation that included liver function test enzymes and complete blood picture that was documented in each patient's medical record.

Disease

- $\mathrm{HBV}+\mathrm{ve}$

- $\mathrm{HCV}$

- Autoimmune

- Others

\section{Diagnosis}

- Positive HBs Ag of $>6$ months

- Positive for HCV antibody

- Negative to above viruses

- Positive antinuclear antibody

- High Ig G levels

- Altered liver enzymes

- Included: a. cryptogenic

b. schistosomiasis

The above classification and summing of CLD was used because of the small numbers of cases retrieved for each group.

B. Control Group included patients attending Endoscope Unit because of gastric diseases, gastritis, duodenitis and esophageal varicose (all of which do not have any influence on caries prevalence), but were free of any hepatic pathology.

\section{Saliva Collection}

Unstimulated whole saliva was collected by asking each participant to spit accumulated saliva in a graded, sterile tube over a standardized period of 5 minutes. Each sample was measured using a pipette and recorded in millilitres (mls). A ratio of salivary flow/minute was calculated for each sample.

\section{Intraoral Examination}

\section{Tooth Examination of CLD Patients and Control Participants}

Each patient was clinically examined to determine numbers of decayed (D), missing (M) and filled roots (F). Radiographs were not indicated since root lesions are best detected clinically. 
According to Banting ${ }^{[19]}$ root caries was diagnosed in the presence of the following criteria:

1. There was a discrete, well-defined or discolored area.

2. A carious lesion was located either at the cemento-enamel junction or if it was present on the root.

3. Restored lesions were present on the root alone or at the cemento-enamel junction as well.

4. There was decay under a root restoration.

On endoscope day, two members of the research team examined patients using sterile examination kits for each patient and a light torch. Intra-oral examination was performed while the patient was lying on the bed after the endoscopy. Inter-examiner calibration was performed every 5 patients. RCI was used to measure the caries distribution. The index was previously described by Katz, $1981^{[20]}$.

$$
R C I=\frac{\text { Decayed Surfaces }+ \text { Filled Surfaces }}{\text { Decayed }+ \text { Filled }+ \text { Sound Surfaces }} \times 100
$$

Statistical analyses were performed using SPSS program using Chi-Square test, $t$-test and ANOVA as appropriate. $\mathrm{P}$ value was set significant at $<.05$ throughout the analysis. Kappa test was performed for inter- and intra- examiner reliability and reproducibility.

\section{Results}

The study groups included 114 CLD patients and 50 control participants. The CLD patients were 63 males and 51 females, while controls were 25 males and 25 females. The inter- and intra-examiner reliability were $0.84,0.86$, respectively.

A. Root Caries. Root caries was detected in 75 of the 164 endoscopy patients examined. It was significantly higher in CLD patients than in the control subjects $(\mathrm{P}<.008)$ (Table 1$)$. There were significant correlations between RCI and both age and gender of CLD patients and control participants. Root caries was highly prevalent among males, than females (Table 2).

Table 1. Root caries index and salivary flow rate among CLD and control groups.

\begin{tabular}{|l|c|c|c|}
\hline Mean \pm SD & CLD & Control & P Value \\
\hline RCI & $2.50 \pm 5.20$ & $0.34 \pm 1.20$ & $0.008^{*}$ \\
\hline Salivary flow & $.34 \pm .28$ & $.48 \pm .45$ & $0.02^{*}$ \\
\hline
\end{tabular}

$*=$ Significant $\mathrm{p}<.05$ 
Table 2. Comparison of mean RCI in CLD and controls by age groups and gender .

\begin{tabular}{|c|c|c|c|c|}
\hline Age group & $\begin{array}{c}\text { RCI (mean ( SD) } \\
\text { CLD (No.) }\end{array}$ & $\begin{array}{c}\text { RCI (mean ( SD) } \\
\text { Control (No.) }\end{array}$ & F value & P value \\
\hline $15-25 \mathrm{Y}$ & $0.22 \pm .45(4)$ & $0.00 \pm 0.00(4)$ & & \\
\hline $26-50 \mathrm{Y}$ & $1.98 \pm 4.81(55)$ & $0.19 \pm 0.62(30)$ & & \\
\hline $51+\mathrm{Y}$ & $3.46 \pm 4.92(40)$ & $1.61 \pm 3.12(5)$ & & \\
\hline Total & $2.50 \pm 4.82(99)$ & $0.35 \pm 1.25(39)$ & 7.54 & $0.007^{*}$ \\
\hline Gender & $2.9 \pm 5.5(57)$ & $0.14 \pm 0.47(20)$ & & \\
\hline Male & $2.3 \pm 4.8(48)$ & $0.54 \pm 1.70(20)$ & & \\
\hline Female & $2.5 \pm 5.2(105)$ & $0.34(1.20(40)$ & 7.33 & $0.008^{*}$ \\
\hline Total &
\end{tabular}

$*$ Significant $\mathrm{p}<.05$

B. Salivary Flow. There were significant differences in SFR between CLD patients and controls (Table 1). However, there was no significant correlation between salivary flow and RCI in CLD group.

C. Root Caries Pattern. Root caries was detected at higher rate on buccal surfaces than proximal and lingual surfaces (Fig. 1). Generally, posterior teeth were affected more than anterior teeth in CLD patients in contrast to control participants who showed that both anterior and posterior teeth were equally affected. A higher percentage of missing teeth was evident in both CLD and control groups than was filled and decayed teeth (Fig. 2). There was an overall significant value of root caries prevalence in all sites for CLD patients in comparison to the control group. When samples from CLD patients and controls were grouped together, caries was found on $67 \%$ of posterior teeth and $33 \%$ of anterior teeth (Fig. 3) with $60 \%$ of the root caries occurring on the buccal surface (Fig. 4).

\section{Discussion}

The result of this study shows the prevalence and pattern of distribution of root caries in liver diseased patients.

Root caries was evident among subjects of all age groups; however, both cross-sectional and longitudinal studies demonstrated a steady increase in prevalence and incidence with increasing age ${ }^{[21]}$. If root caries prevalence is judged based on the presence of active, restored or arrested lesions, virtually everyone over the age 65 -years is considered affected ${ }^{[22,23]}$. In agreement with other studies, the results of the current study show an increase of root caries incidence with age above 35 -years ${ }^{[21,24-27]}$. This may be explained by the possibility of medicine side-effects and illnesses that might result in neglect of oral hygiene and dental care ${ }^{[28]}$. Chronic disease can also be a contributor to diminished oral 


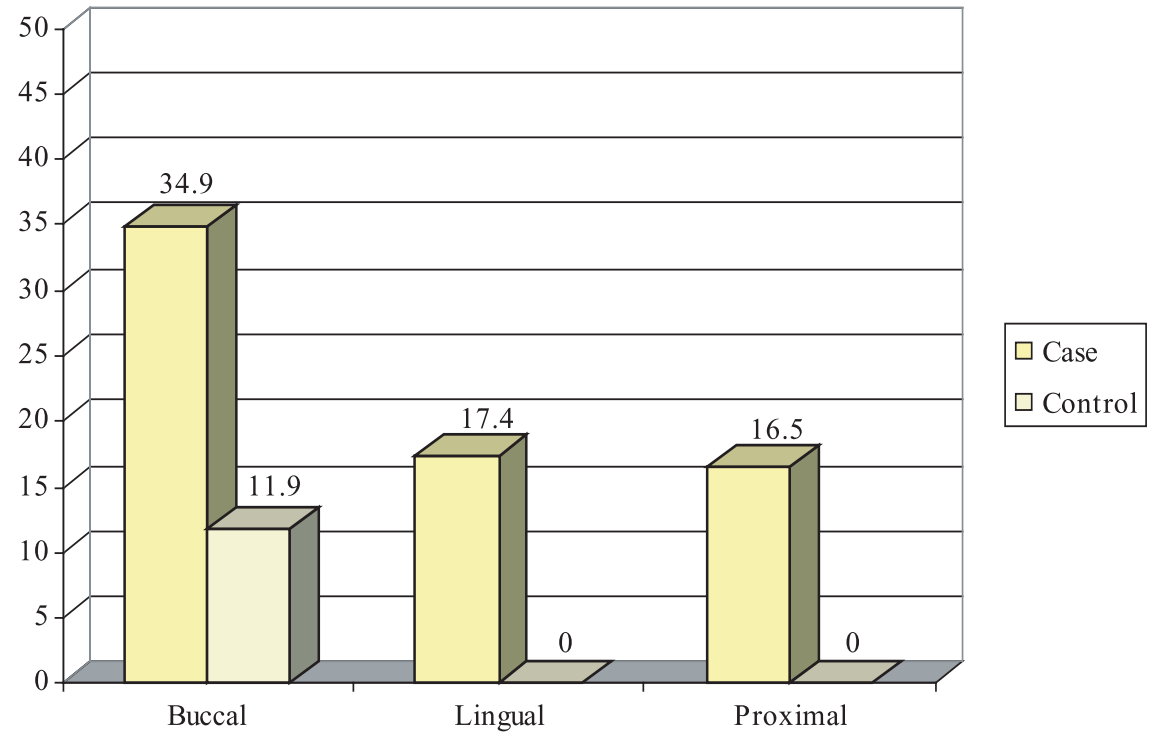

Fig. 1. The percentage of root caries in the buccal, lingual, and proximal surface in CLD and control group.

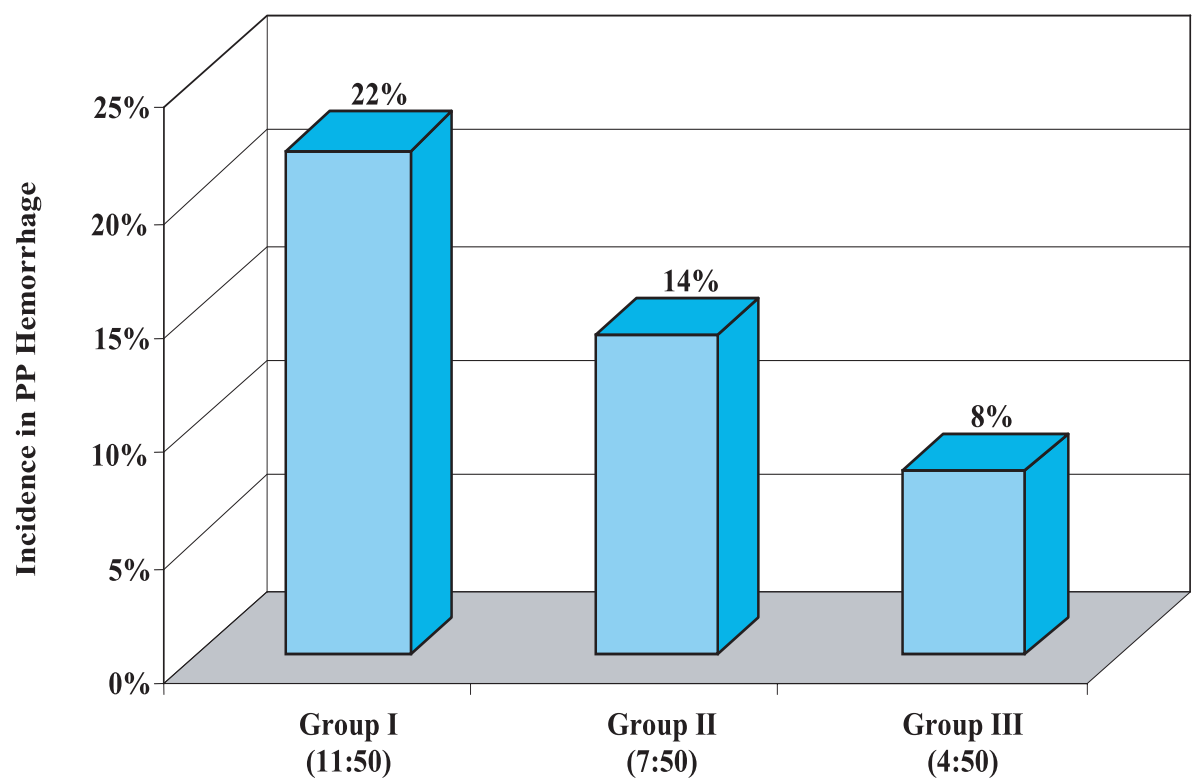

Fig. 2. Frequency distribution of affected anterior, posterior teeth and DMF roots among, CLD and control group. 


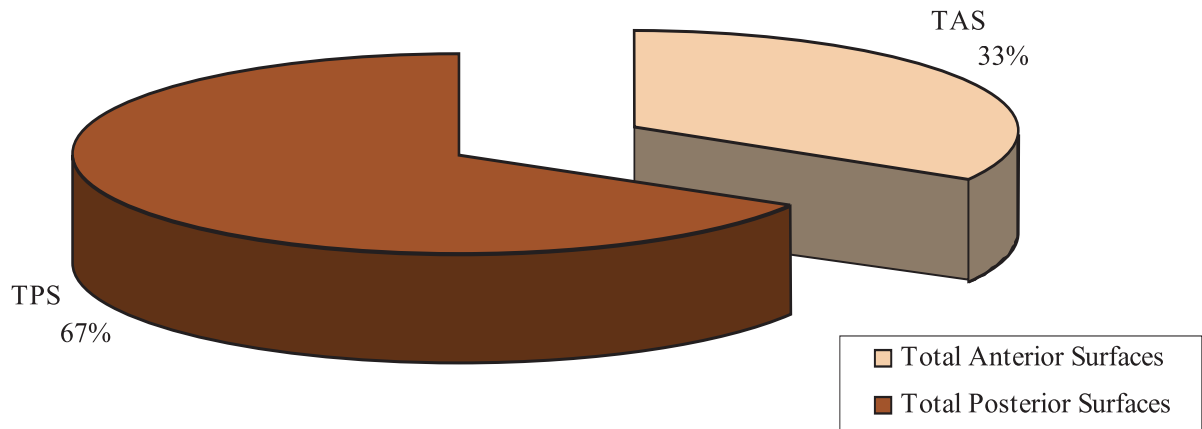

Fig. 3. Frequency distribution of affected anterior, posterior teeth and DMF roots among, CLD and control group.

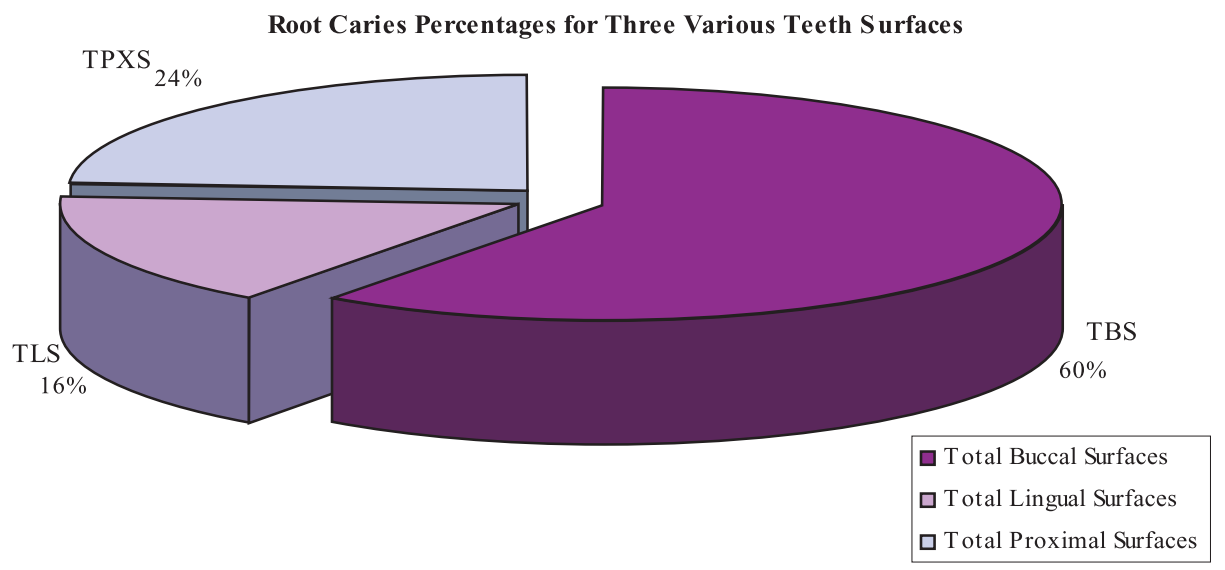

Fig. 4. The percentage of root caries in proximal, lingual and buccal teeth among the whole study group.

hygiene efficacy because of impairments in functions such as vision or manual dexterity ${ }^{[5]}$. The shift from extraction to more endodontic treatment will increase the number of retained teeth in the adult population, this results in higher number of root surface at risk for caries. The increased number of retained teeth and higher incidence of gingival recession are considered of key importance to the risk of developing root caries in old age ${ }^{[5,6]}$.

There was further similarity in this study with investigation by others, as to gender-associated high root caries where males recorded higher RCI than females ${ }^{[16,29-33]}$. This could be attributed to differences in dental care behavior 
of women with respect to higher frequency of tooth-brushing, less sugar consumption and more regular dental check ups.

Salivary metabolic disorders with altered levels of calcium; higher inorganic phosphorus and Alkaline phosphatase (ALP) activity was reported to predispose to high caries rates and rampant caries in children ${ }^{[34]}$. This might explain the high percentage of RCI in CLD patients that was correlated with a high level of ALP that manifested in the enzyme investigation of CLD patients. Further investigation is required for adults, with expected subsequent influence of ALP on caries incidence in all ages.

The significance of the effect of liver dysfunction on salivary glands was reported by Glick ${ }^{[35]}$. In this study, the salivary flow was significantly lower in the CLD patients than in the control group. This reduction could be related to medication intake or the severity of illness of the diseased patient. Recent studies have revealed that the mean of drug intake increased with age from 0.9 in 55-year-olds to 2.4 in the 85 -year-olds, having an inverse relationship between salivary flow and the number of drug intake ${ }^{[36]}$. A significant relationship between salivary parameters, such as buffer capacity, flow rate and plaque index was found in elderly population ${ }^{[37]}$. Despite seemingly low salivary flow rate, a person's oral environment may not be favorable for root caries development. Therefore, lack of association of low salivary flow and occurrence of root caries in cross-sectional studies is not surprising ${ }^{[38,39]}$. This assumption supports the present results which showed non-significant correlation between RC and SFR among the CLD group.

The high rate of affected buccal surfaces with root caries in this study, is in agreement with other studies in reporting the high incidence of non-carious cervical lesions such as gingival recessions and wedge shaped defects which are most often found on buccal surface and are highly susceptible to caries ${ }^{[40-42]}$. Although it is expected that interproximal carious lesions occur more frequently than buccal and lingual lesions ${ }^{[21,28]}$. The present study failed to support this assumption; this could be attributed to the diagnostic method that relied completely on clinical examination without using radiograph to confirm the presence of caries, which has probably under estimated the true prevalence and incidence of interproximal lesions.

Missing and decayed teeth exhibited a higher percentage than filled teeth in this study. In contrast, reports from United States of America and Europe indicate that filled teeth are most prevalent ${ }^{[15,16,33]}$. This could be due to the infrequent use of dental services, lack of social support network, less education, and physical debility and dependency. Also the ongoing loss of teeth with age is likely to produce an under estimation of the prevalence of root caries ${ }^{[21]}$. It was concluded that dental health behavior influences root caries occurrence and that caries on root surfaces is associated with poor dental health habits ${ }^{[29]}$. 
The examiners didn't attempt to ascertain the underlying cause of missing teeth. Therefore, teeth could have been extracted because of periodontal disease, trauma, or coronal caries. It was difficult for CLD patients who were prepared for endoscopies to recall the exact reasoning for extraction. The assumption that teeth are missing because of caries is documented by the World Health Organization's protocol ${ }^{[43]}$.

The percentage of posterior root caries is greater than that of anterior teeth. This may be attributed to the difficulty in accessing those teeth by the patients. Studies have indicated that individuals who have coronal caries are 2-3.5 times more likely to develop root caries ${ }^{[30,44]}$. Also, ethnicity is a relatively new variable in caries studies because of the difficulty in obtaining appropriate sample population sizes ${ }^{[45,46]}$. Further, studies showed that the prevalence among susceptible surface in the mandible is highest posteriorly and the opposite is true for the maxilla ${ }^{[20,28,47,48]}$.

Interpretation of data from prevalence and incidence studies is difficult due to differences in diagnostic criteria, treatment decisions and lack of homogenicity of the observed population ${ }^{[49]}$. Root caries, similarly to many diseases common in old age groups, is reflective of a problem in more than a single organ system, and its resolution may therefore require the efforts of professionals from more than one discipline.

\section{Conclusions}

The study shows high root caries prevalence in CLD compared to the control and the difference was statistically significant. This was attributed to low salivary flow rate seen in the CLD patients. Root caries were significantly higher on the buccal surfaces compared to other surfaces and in the posterior teeth more than the anterior. Root caries was found significantly higher in male than female in both groups. Root caries index increased as age increase. Root caries incidence was found to be further complicated by other advancing age factors.

\section{References}

[1] Grigsby JS. Paths for future population aging. Gerontologist 1991; 31(2): 195-203.

[2] Ber Key D, Berg R. Geriatric oral health issues in the United States. Int Dent J 2001; 51(3 Suppl): 254-264.

[3] [No Authors Listed]. Oral health of US Adults: NIDR. 1985 National Survey. J Public Health Dent 1987; 47(4): 198-205.

[4] Novacek G, Plachetzky U, Potzi R, Lentner S, Slavicek R, Gangl A, Ferenci P. Dental and periodontal disease in patients with cirrhosis - role of etiology of liver disease. $J$ Hepatol 1995; 22(5): 576-582.

[5] Shay K. Root caries in the elderly: an update for the next century. J Indiana Dent Assoc 1997-1998; 76(4): 37, 39-43. 
[6] Watanabe MG. Root caries prevalence in a group of Brazilian adult dental patients. Braz Dent $J$ 2003; 14(3): 153-156.

[7] Landahl S. Drug treatment in 70-82-year-old persons. A longitudinal study. Acta Med Scand 1987; 221(2): 179-184.

[8] Osterberg T, Landahl S, Hedegard B. Salivary flow, saliva, $\mathrm{pH}$ and buffering capacity in 70-year-old men and women. Correlation to dental health, dryness in the mouth, disease and drug treatment. J Oral Rehabil 1984; 11(2): 157-170.

[9] Czaja AJ. Extrahepatic immunologic features of chronic viral hepatitis. Dig Dis 1997; 15 (3): 125-144.

[10] Bagan JV, Alapont L, del Olmo JA, Rodrigo JM, Lloria E, Jimenez Y. Dental findings in patients with liver cirrhosis. A study of 100 cases. Bull Group Int Rech Sci Stomatol Odontol 1996; 39(3-4): 77-79.

[11] Pirisi M, Scott C, Fabris C, Ferraccioli G, Soardo G, Ricci R, Toniutto P, Avellini C, Vitulli D, Miotti AM, et al. Mild sialoadenitis: A common finding in patients with hepatitis C virus infection. Scand J Gastroenterol 1994; 29(10): 940-942.

[12] Tempestini O. [Periodontal diseases and liver]. Riv Ital Stomatol 1970; 25(1): 3-8.

[13] Imhof M, Popal H, Lee JH, Zeuzem S, Milbradt R. Prevalence of hepatitis C virus antibodies and evaluation of hepatitis $\mathrm{C}$ virus genotypes in patients with lichen planus. Dermatology 1997; 195(1): 1-5.

[14] Shobokshi O. Epidemiology of viral hepatitis in Saudi Arabia. Recent advances in liver diseases and transplantation. King Fahd National Guard Hospital, Riyadh: April, 1998.

[15] Winn DM, Brunelle JA, Selwitz RH, Kaste LM, Oldakowski RJ, Kingman A, Brown LJ. Coronal and root caries in the dentition of adults in the United States, 1988-1991. J Dent Res 1996; 75: 642-651.

[16] Splieth Ch, Schwahn Ch, Bernhardt O, John U. Prevalence and distribution of root caries in Pomerania, North-East Germany. Caries Res 2004; 38(4): 333-340.

[17] Vehkalahti V. Occurrence of root caries and factors related to it. Proc Finn Dent Soc 1987; 83 (Suppl 4-5): 1-99.

[18] Salonen L, Allander L, Bratthall D, Togelius J, Hellden L. Oral health status in an adult Swedish population. Prevalence of caries. A cross-sectional epidemiological study in the Northern Alvsborg county. Swed Dent J 1989; 13(3): 111-123.

[19] Banting DW, Courtright PN. Distribution and natural history of carious lesions on the roots of teeth. Dent $J$ 1975; 41(1): 45-49.

[20] Katz RV. Root caries: clinical implications of the current epidemiologic data. Northwest Dent 1981; 60(6): 306-310.

[21] Beck JD. The epidemiology of root surface caries: North American studies. Adv Dent Res 1993; 7(1): 42-51.

[22] Zambon JJ, Kasprzak SA. The microbiology and histopathology of human root caries. Am J Dent 1995; 8(6): 323-328.

[23] Fejerskov O. Recent advancements in the treatment of root surface caries. Int Dent $J$ 1994; 44(2): 139-144.

[24] Banting DW, Ellen RP, Fillery ED. Prevalence of root surface caries among institutionalized older persons. Community Dent Oral Epidemiol 1980; 8(2): 84-88.

[25] Banting DW, Ellen RP, Fillery ED. A longitudinal study of root caries: baseline and incidence data. J Dent Res 1985; 64: 1141-1144.

[26] Katz RV, Hazen SP, Chilton NW, Mumma RD Jr. Prevalence and intraoral distribution of root caries in an adult population. Caries Res 1982; 16(3): 265-271.

[27] Lohse WG, Carter HG, Brunelle JA. The prevalence of root surface caries in a military population. Mil Med 1977; 142(9): 700-703. 
[28] Kitamura M, Kiyak HA, Mulligan K. Predictors of root caries in the elderly. Community Dent Oral Epidemiol 1986; 14(1): 34-38.

[29] Vehkalahti MM, Paunio IK. Occurrence of root caries in relation to dental health behavior. $J$ Dent Res 1988; 67(6): 911-914.

[30] Papas A, Joshi A, Giunta J. Prevalence and intraoral distribution of coronal and root caries in middle-aged and older adults. Caries Res 1992; 26(6): 459-465.

[31] Fejerskov O, Baelum V, Ostergaard ES. Root caries in Scandinavia in the 1980's and future trends to be expected in dental caries experience in adults. Adv Dent Res 1993; 7(1): 4-14.

[32] Narhi TO, Vehkalahti MM, Siukosaari P, Ainamo A. Salivary findings, daily medication and root caries in the old elderly. Caries Res 1998; 32(1): 5-9.

[33] Fure S, Zickert I. Prevalence of root surface caries in 55-, 65-, and 75-year-old Swedish individuals. Community Dent Oral Epidemiol 1990; 18(2): 100-105.

[34] Pandey RK, Tripathi A, Chandra S, Pandey A. Relation of salivary phosphorus and alkaline phosphatase to the incidence of dental caries in children. J Pedod 1990; 14(3): 144-146.

[35] Glick M. Know thy hepatitis: A through TT. J Calif Dent Assoc 1999; 27(5): 376-385.

[36] Fure S. Ten-year cross-sectional and incidence study of coronal and root caries and some related factors in elderly Swedish individuals. Gerodontology 2004; 21(3): 130-140.

[37] Guivante-Nabet C, Berenholc C, Berdal A. Caries activity and associated risk factors in elderly hospitalized population--15-months follow-up in French institutions. Gerodontology 1999; 16(1): 47-58.

[38] Soderholm G, Birkhed D. Caries predicting factors in adult patients participating in a dental health program. Community Dent Oral Epidemiol 1988; 16(6): 374-377.

[39] Younger H, Harrison T, Streckfus C. Relationship among stimulated whole, glandular salivary flow rates, and root caries prevalence in an elderly population: a preliminary study. Spec Care Dentist 1998; 18(4): 156-163.

[40] Lussi AR, Schaffner M, Hotz P, Suter P. Epidemiology and risk factors of wedge-shaped defects in a Swiss population. Schweiz Monatsschr Zahnmed 1993; 103(3): 276-280.

[41] Levitch LC, Bader JD, Shugars DA, Heymann HO. Non-carious cervical lesions. J Dent 1994; 22(4): 195-207.

[42] Kassab MM, Cohen RE. The etiology and prevalence of gingival recession. J Am Dent Assoc 2003; 134(2): 220-225.

[43] World Health Organization. Oral Health Survey, Basic Methods. 2nd ed. Geneva: WHO 1977 ; 37-41.

[44] Hand JS, Hunt RJ, Beck JD. Incidence of coronal and root caries in an older adult population. J Public Health Dent 1988; 48(1): 14-19.

[45] Powell LV, Leroux BG, Persson RE, Kiyak HA. Factors associated with caries incidence in an elderly population. Community Dent Oral Epidemiol 1998; 26(3): 170-176.

[46] Ravald N, Birkhed D, Hamp SE. Root caries susceptibility in periodontally treated patients. Results after 12 years. J Clin Periodontol 1993; 20(2): 124-129.

[47] Gustavsen F, Clive JM, Tveit AB. Root caries prevalence in a Norwegian adult dental patient population. Gerodontics 1988; 4(5): 219-223.

[48] Wallace MC, Retief DH, Bradley EL Jr. The prevalence of root caries in population of older adults. Gerodontics 1988; 4(2): 84-89.

[49] Clarkson JE. Epidemiology of root caries. Am J Dent 1995; 8(6): 329-334. 
نسبة انتشار وتوزيع تسوس الجذور في مرضى الكبد السعوديين

\section{هناء محمد جمجوم}

قسم إصحاح الأسنان ، كلية طب الأسنان ، جامعة الملك عبدالعزيز

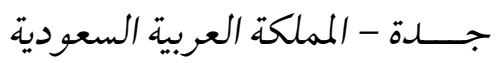

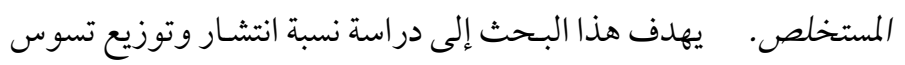
جذور الأسنان في المرضى السعوديين المصابين بأمراض الكبد الفيروسية. من الثابت علميا أن ظاهرة تسوس جذور الأسنان تنتشر في عدد كبير

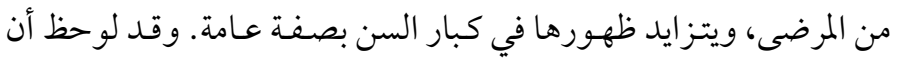

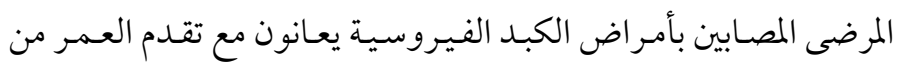

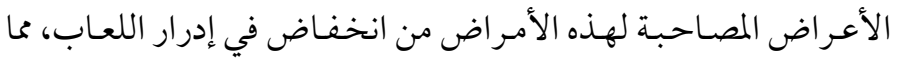
يزيد من احتمالات تسوس الأسنان والجذور.

تتكون عـينة هذا البحث مـن ع 17 مريضًا قسـمت إلى مجمهـوعتين

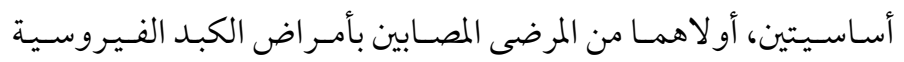

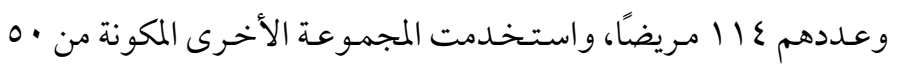

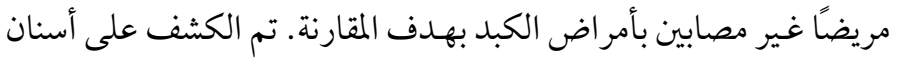

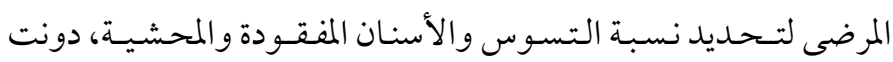

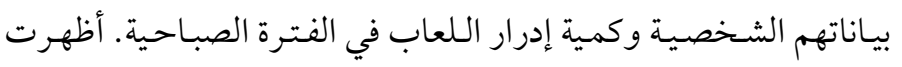

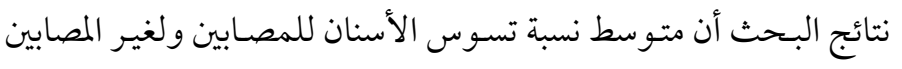

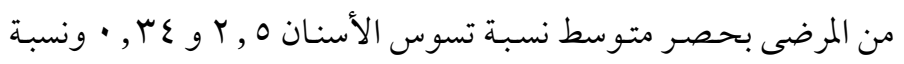

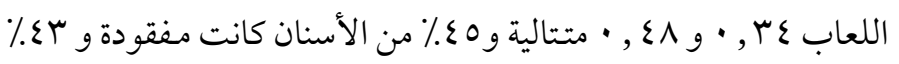
مصابة بالتسوس.

أظهرت النتائج المدعمة بالتحليل الإحصائي أن هـناك تناسبًا طرديًا بين

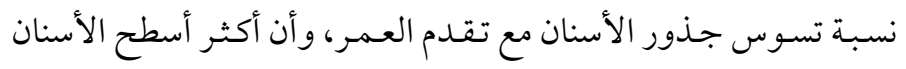
المعرضة لهذا التسوس، هي السطوح الأمامية من الأضر اس الخدان آلفية. 